\title{
Wanda Morla en París de los años veinte: una experiencia de la modernidad
}

\author{
Wanda Morla in Paris during the Twenties: \\ an Experience of Modernity
}

\author{
Patricio Lizama A. \\ Pontificia Universidad Católica de Chile \\ plizama@uc.cl
}

En el texto se analizan las cartas escritas en 1922 en París por Wanda Morla relevancia de la carta como documento y discurso amoroso, y se profundiza en el "encuentro fortuito" de estos jóvenes en París, en cómo Wanda Morla se reconstruye alejándose del modelo de mujer vigente en la elite chilena de la época y en su experiencia de la modernidad en el campo cultural francés, en particular el musical, entre 1921 y 1922.

Palabras clave: Carta, azar, predestinación, reconstrucción mujer, modernidad, campo musical francés.

The letters written in Paris in 1822 by Wanda Morla to Domingo Santa Cruz-then residing in Madrid-are analyzed in terms of the pertinence of the letter both as a document and a statement of love. The "fortuitous encounter" in Paris of these two youngsters is studied in depth, along with the process of selfconsciousness of Wanda Morla as a person different from the feminine stereotype then current among the Chilean elite. Besides her experience of the cultural modernity in France between 1921 and 1922, in particular as pertains to music, is discussed.

Keywords: Letter, chance, predestination, feminine selfconsciousness, modernity, French musical field.

El libro Pájaro libre como soy. Cartas de Wanda Morla Lynch, es un valioso epistolario que edita Wenceslao Díaz y que publica Ediciones Universidad Católica de Chile ${ }^{1}$. Las cartas, ciento noventa y ocho en total, son de Wanda Morla quien desde París le escribe a sus hermanas en Santiago, y luego a Domingo Santa Cruz quien reside en Madrid. Él inicia en esta ciudad su carrera diplomática como segundo Secretario de la Legación de Chile e ingresa al Real Conservatorio Superior para realizar estudios de composición con el violista y compositor Conrado del Campo. El libro contiene una breve nota inicial escrita por Pedro Lastra y luego una introducción de Wenceslao Díaz que explicita las trayectorias de Wanda y Domingo, caracteriza a otras mujeres chilenas -Luisa Lynch, madre de Wanda, Eugenia Huici, amiga de Pablo Picasso, Igor Stravinsky y otros actores centrales de la vanguardia de la época-, y revela la manera en que encontró las cartas².

${ }^{1}$ Una primera versión de este texto fue leída al presentar el libro de Wenceslao Díaz en diciembre de 2013. Para su publicación en $R M C h$, se realizaron algunos cambios.

2 Luisa Lynch fue una mujer destacada en el campo cultural de principios de siglo XX en Chile y pertenece al llamado feminismo aristocrático. Eugenia Huici, casada con el pintor José Tomás 
La búsqueda y recopilación de este valioso material se suma a los anteriores libros publicados por Díaz. El primero, Juan Francisco González: cartas y otros documentos de su época, permite conocer los viajes de este pintor a Europa, sus disputas plásticas a comienzos del siglo XX y la relevancia de sus clases y de su práctica artística, tareas que lo convierten en un referente para la generación que dará origen al Grupo Montparnasse y a la renovación plástica a partir de 1923. El segundo, Bohemios en París - Epistolario de artistas chilenos en Europa, 1900-1940, revela los viajes de pintores de distintas generaciones y tendencias al viejo continente, muestra cómo ellos se enfrentaron a las nuevas corrientes del arte en Europa, a veces ignorándolas, otras veces modificando sus creencias aprendidas en Chile, y retrata con nitidez la compleja trama de instituciones, actores y polémicas del campo pictórico chileno de inicios del siglo XX. Destacaremos algunos de los aspectos más significativos de esta nueva publicación de Díaz.

\section{LA CARTA: DOCUMENTO HISTÓRICO Y DISCURSO AMOROSO}

La carta, comunicación escrita que siempre es diferida en el tiempo entre espacios distintos, constituye en este libro un valioso documento histórico. Conocemos entretelones de la vida diplomática y de la elite chilena en Francia, en especial los relativos a Carlos Morla Lynch, hermano de Wanda que más tarde trabajó en la embajada de Chile en Madrid durante la guerra civil española ${ }^{3}$. Nos informamos con gran detalle y juicio crítico de la pintura, el ballet y el teatro que Wanda ve en París, pero el arte que ella comenta con mayor amplitud es la música, la clásica y la moderna. De este modo el epistolario ofrece una mirada exhaustiva del campo musical francés de los años veinte. Wanda toma clases de piano con Madeleine de Valmalète, asiste a ensayos y conciertos al antiguo conservatorio, a la Salle Gaveau, aprecia la música del pasado, sus intérpretes, sus escenarios, sus profesores, así como también las nuevas propuestas del presente que surgen en particular entre los inmigrantes rusos a quienes ella conoce.

La carta es al mismo tiempo una comunicación que tiene lugar para compensar la ausencia y, en este sentido, informa sobre el remitente y su receptor de múltiples formas. En esta correspondencia se entreabre el universo privado de dos jóvenes y se percibe la intimidad de la experiencia amorosa, la cual muestra el anverso y el reverso que suponen los viajes y las distancias entre los amantes. Surgen así las paradojas que articulan a la carta amorosa: presencia/ausencia; proximidad/distancia; imaginario/real. Domingo y Wanda se conocen en Santiago, se reencuentran por casualidad en París en febrero de 1922, comienzan a escribirse con frecuencia e inician la relación sentimental cuando ella viaja a Madrid en mayo de 1922, pero luego se distancian pues la joven regresa a París y él permanece en la capital española dedicado a su trabajo y a sus estudios musicales. Cuando Wanda y Domingo inician su relación, el epistolario, sin excluir la referencia a los acontecimientos artísticos, da cuenta del amor de la pareja, de los planes que desarrollan para casarse y concluye con el matrimonio celebrado en enero de 1923 en París. Por último, se agregan algunas cartas de Luisa Lynch a su hija Wanda quien empieza su nueva vida en Madrid.

Errázuriz, se separó de él y permaneció en Francia donde se convirtió en amiga y mecenas de varios artistas fundamentales de la vanguardia contemporánea.

3 Ver Morla Lynch 1958. 


\section{EL ENCUENTRO EN PARÍS: AZAR Y PREDESTINACIÓN}

Wanda y Domingo se juntan en forma casual en París en febrero de 1922. París era una fiesta como dice Ernest Hemingway, época de "los años locos", y, para estos dos jóvenes chilenos, 1922 también será una fiesta. El encuentro entre Wanda y Domingo se vincula al azar y surge en un momento crítico en la vida de la joven Morla, pues ella viaja con su madre a Europa en enero de 1921 para superar el quiebre de su primer amor en Chile. Instalada desde junio de 1921 en París, un día de febrero del año siguiente asiste con su madre a un concierto de órgano en el Conservatorio y en la puerta ven a Santa Cruz que desea entrar, pero no tiene invitación. Luisa Lynch le dice al portero que él es su hijo y ese día, Domingo ingresa al concierto, a la vida de Wanda y a la familia Morla.

El encuentro fortuito como sostienen los surrealistas, está mediado por predestinaciones y sincronías. La posibilidad de hallar un amor se la habían anunciado a Wanda en enero de 1921 en Los Andes, antes de abordar el Ferrocarril Transandino que las llevaría a Buenos Aires y de allí a Europa, cuando su hermana Carmen le ve las cartas y le confiesa: "Te casarás con quien tú quieras" $(45)^{4}$. Wanda recuerda ese episodio unos pocos días después en enero de 1921 en Buenos Aires y le escribe a Carmen: "No sé qué diera por obtener lo que deseo. He recordado mucho tu consoladora frase en Los Andes" (45). Agreguemos que las hermanas Morla se distinguen por sus prácticas espiritistas y por sus conocimientos ocultistas, de modo que la revelación recibida no era un hecho menor para Wanda.

La música es lo que une a los jóvenes y Domingo subraya cómo esta primera experiencia en el conservatorio resulta el fundamento que acerca para siempre a la pareja: "Fui admitido de inmediato [al concierto] y, por primera vez, con Wanda ¡nos sentamos a escuchar la música que debía unirnos para siempre!”(25). Por su parte, Wanda le escribe a su hermana Ximena días después del encuentro, cuando Domingo todavía permanece en París: "Oh milagros de la vida europea -en París, ciudad inmensa donde el individuo se pierde, Wanda Morla y Domingo Santa Cruz caminando a tomar el Métroy después sentados en un banco frente a un altar muy sobrio con solo una cruz de argento y una gran Biblia abierta, mientras arriba el órgano, la orquesta y las voces elevaban hacia el cielo las más tiernas demostraciones" (63).

El lugar donde se encuentran también es significativo pues el conservatorio parisino se ubica en el número 14 de la calle Madrid, capital donde vive y desde donde viaja Santa Cruz. La sincronía descubierta por Wanda relacionada con la proximidad de las fechas de celebración de los nombres propios Domingo y Nieve, es otra sorprendente manifestación del azar. En carta del 31 de marzo, ella le confiesa a Domingo (116):

"Leyendo en La Légende Dorée sobre el santo de su nombre Saint Dominique confesseur, he visto con alegría que nuestros nombres de pila son como hermanos; pues usted ha de saber que me llamo Wanda Nieve y si Santo Domingo se honra el 4 de agosto, el día 5 del mismo mes se glorifica el nombre de nuestra Señora de las Nieves. Cuando chica esa fecha era toda mi ilusión y la víspera (el día 4) era el día más luminoso de la espera. Esa coincidencia me parece digna de serle contada ¿no encuentra?”.

Inevitable es añadir que el día que se reúnen en el conservatorio cae nieve, lo mismo que sucede el día que se casan en París. Y en ambas ocasiones lo que escuchan son obras para órgano de Johann Sebastian Bach.

La joven Morla, por último, hace una lectura religiosa del episodio que los une. Le escribe a Domingo en marzo de 1922 y afirma: “yo también creo que es Dios que ha querido

4 Los números entre paréntesis hacen referencia a la página en Morla 2013. 
este encuentro en un momento tan propicio, seguramente si nos hubiéramos visto en Chile con más frecuencia y en años anteriores no habría sido lo mismo" (84). En junio de 1922, cuando ya son pareja, le señala que al leer El corazón secreto de Pierre Aguétant, se interesó por los "Nada infinitos" y comprende que un "Nada" de su vida es "nuestro encuentro simpático en el Conservatorio". Estos "nada", según Aguétant, tienen en el amor "una importancia excepcional. Ocultos en la sombra, esperan la ocasión propicia para iluminarnos, encantarnos o traicionarnos". Wanda agrega: "este "nada" ... había sido escrito por Dios" y concluye: "soy como predestinada" (216).

Sincronía del azar mediada por el arte, predestinación interpretada desde la fe y anticipada en el tarot, son realidades que están en la base de este epistolario y que configuran la original identidad de Wanda.

\section{WANDA FUERA DE LUGAR: LA RECONSTRUCCIÓN DE UNA JOVEN DE ELITE EN PARÍS}

En el epistolario advertimos rasgos de la formación y los modos de comportamiento de la elite chilena, creencias y conductas que Wanda enjuicia y de las cuales se distancia con nitidez. En Chile a los 17 años, ella se sabe inestable y admite que atraviesa un periodo de cambio, proceso que percibe como transitorio. A su hermana Carmen le comenta "que la complejidad de los sentimientos que experimento solo depende de la transición en que me encuentro" (43). Agrega: "hay momentos de feminidad y otros en que me siento totalmente niña; es suficiente para probar que puedo sentir como si tuviera dos corazones" (44). Años más tarde, confiesa a Domingo que "al venirme a Europa era yo todavía una chiquilla, sin carácter definido ... y sin dirección estable". Añade que tenía "muchas aspiraciones para ser buena y unos ideales forjados por intuición formaban todo mi ser íntimo, pero era todo mal definido, inquieto y sin contornos" (84). Lo único seguro era su deseo de tener una familia, profundizar su formación artística, mantener su vínculo con la bailarina rusa Ana Pavlova, su "madre espiritual" conocida en Santiago y que visita en París, y otorgarle una proyección trascendente a su vida.

En la capital francesa, Wanda define sus anhelos y afirma su autonomía pues se aleja del horizonte existencial inscrito en su familia. Su independencia la experimenta "a los 19 años, cuando empecé a ser una persona pensante, cuando empecé a ver más claro mi propia personalidad e inclinaciones" (147). Ella rechaza la vida diplomática y la vida mundana de compromisos sociales y recepciones, de fiestas y salones con personas que se "las dan de elegantes" y que son muy superficiales. A la vez, reniega de quienes asumen a París como el lugar donde esta vida mundana se vive con mayor distinción, pues sostiene que este mundo "chic" es artificial, vacío y lleno de vanidad. Le escribe a su hermana Carmen en 1921 (58):

"París es una ciudad de la tierra, en ella no hay hadas ni genios como en los bosques encantados; hay simplemente hombres de todas castas, de todas clases, de todas razas, ideas y religiones. Hay lujo e inconsciencia; hay medios distinguidos donde se ven mujeres bien vestidas, bien pintadas, bien falsas ... Hay falta de dignidad, cancans de malas lenguas y la vanidad pasea por los salones mientras la moral, sujetando por las alas al amor, llora en el umbral de las puertas. Ese es el mundo chic que solo conocemos de referencia".

A su hermana Ximena que cree a Wanda y a su madre "en medio del mundo chic", le pregunta: "El mundo chic ¿dónde está? Esas mujeres que llevan trajes de 3.000 frs., que van a bailar o a cenar a los restaurantes; que bailan el Shimmy como muñecas epilépticas, que se dan aires y coquetean. ¿A eso te refieres?” Concluye: "Cada día siento la mentira en todo esto" (56).

En octubre de 1922, le escribe a Domingo y reitera su desacomodo (356): 
"Más que nunca creo que la vida social y la mundana son hermanas y que en ellas solo se sienten bien los seres que necesitan remudar de casa y de pensamientos, los que les gusta el flirt (pongo esa palabra tan antipática por necesidad de expresión), el bailoteo y las diversiones de poco vuelo espiritual. No tengo carácter para ella, soy como vieja, me daba hoy una flojera terrible de hablar y me pasé mirando a todos como si fueran cajitas mecánicas con forma de muñecos, y con mi alma puesta en ti. ¡Qué falta me haces, mi hijito! Contigo no me sentiría fuera de centro en ninguna parte pues siempre tendríamos algo que comentar o considerar".

La misma incomodidad le genera el mundo femenino preocupado de la ropa y de la moda, del vestido de fiesta y de las visitas a las modistas. Debido a su austeridad, ella tiene un juicio ético-moral acerca de estas vivencias (108):

“...me puedo familiarizar con esos lujos y le aseguro que no quiero porque considero simplemente inmoral el pagar por un trapo, por precioso que sea, lo que equivale al sueldo de cualquier modesto empleado de comercio. Cuando voy a esas partes es tal la rebelión de sentimientos que se levantan contra mí misma al verme tentada por algo que, dentro del presupuesto que me he marcado con mi conciencia, pasa a ser demasiado, que más bien se vuelve la tal ida un momento desagradable. ¿Comprende ahora que prefiera evitar esas tardes perdidas en los salones de costura? ... Me vienen todo el tiempo los pensamientos familiares y me encuentro muy fuera de lugar".

La vanidad y el vacío de estas preocupaciones son también juzgadas con claridad: "Sería muy agradable ser elegante si no se fuera vaciando el interior poco a poco por ocuparse de los trapos que solo duran una estación del año y deja, entre una satisfacción de los primeros días, un dejo de decepción cuando se tiene un poco de conciencia” (96).

La independencia de Wanda se expresa respecto al modelo de mujer impuesto por la sociedad patriarcal que impulsa a la mujer a casarse, tener hijos y depender del hombre. Ella cuestiona la ideología de la domesticidad dominante y el papel femenino subalterno, busca liberarse de restricciones y prácticas enraizadas y define un marco discursivo propio con otras perspectivas, que le permiten construir otros sujetos femeninos y proponer subjetividades alternativas, aunque siempre inmersas en la tensión de la cultura donde está inserta. A Ximena le dice en 1921 (53):

"No pienses que soy pretenciosa, esto no es orgullo, es dignidad, y es lo que me aleja cada vez más de la idea de casarme por lo que se casa la gente en general, para no quedarse sola y ser inútil en la vida. Siento en mi destino de mujer una gran misión; si no encuentro a una persona que la comprenda como yo para cumplir la que Dios señaló, desde la creación del mundo, al hombre y a la mujer, de unirse para dar a la Tierra seres fuertes y dignos, si no encuentro un compañero que me ayude... sé que todo este sentimiento de desahogo maternal que tengo no se perderá”.

$\mathrm{Al}$ saberse distinta y con mayor madurez, declara con energía: "sé muy bien lo que quiero" y agrega que tiene "derecho para pensar como yo quiero y creo justo" (320).

Su diferencia le provoca un retraimiento y un "estado de acritud" que no es aceptado ni comprendido en su familia. Su madre la critica y le hace observaciones; su hermano diplomático la contradice y la tilda de beata y Wanda siente "el muro y ... el abismo que me separa de los seres que son de mi sangre" (320). Ella es una extraña en el mundo, una exiliada del ámbito familiar y su necesidad de autoafirmación la lleva, al igual que los artistas de los relatos de Rubén Darío, a buscar un refugio: "Prefiero por mucho, estar en mi cuartito azul de Rue Lisbonne, donde tantas cosas me respetan" (108). Wanda soluciona lo denunciado por Virginia Woolf porque la mujer en este caso tiene "un cuarto propio": ella convierte "su buhardilla, en un reino".

La capacidad crítica y autorreflexiva de Wanda le brindan un acabado conocimiento de sí misma de modo que al conocer a Domingo, entiende de inmediato que con él puede 
terminar de articularse una identidad con un origen y un destino nuevos. Ella comparte con el joven Santa Cruz el amor por la música, el arte "más sublime", y a la vez el amor por Dios porque para Wanda la música es también el arte "más cerca de Dios" y el que le permite evangelizar y "aportar algo bueno y más elevado a una sociedad" (107). De este modo, en la visión de Wanda el amor humano y la música están imbricados y constituyen dos mediaciones para acceder a la divinidad. Por esto es que al pensar el regreso a Chile, se imagina casada con una vida sencilla orientada a difundir "día a día en todos los círculos, algo verdaderamente bueno -con base- escogido, sin otro fin que el de acercar por medio de grandiosos conciertos espirituales, muchas almas buenas a Dios" (107).

$\mathrm{Al}$ mismo tiempo, se construye un origen alternativo que también pasa por el vínculo entre el arte y la fe. En Santiago, la joven Morla halla una "madre espiritual" en la bailarina Anna Pavlova: "la venero con adoración mística", a quien llama "Ella" y "Madame"; en París la ve de nuevo porque "es la única, el único ser que me volvió a dar por unos días el perdido sentimiento de felicidad" (54). En esta misma capital encuentra en Johann Sebastian Bach un "padre" porque para ella, la obra de este compositor la conduce a la trascendencia. Con toda convicción, Wanda afirma: “... es que Bach, Domingo, es más que música, es toda una obra de fe y de amor a Dios" (111). En otra carta, Wanda sostiene: "Bach para mí es algo más que un genio en la música, es un santo que hace sentir a Dios" (87). Agrega que "siento por él una veneración y lo tomo para mi vida... como un bienhechor espiritual" (87). Como a Domingo el músico alemán le provoca una experiencia muy semejante, ella le dice: Es "Nuestro Padre" (152), y también "nuestro venerado Padre y mediador" (194).

Su proyecto existencial lo define como una misión, una vida protegida y encaminada hacia la divinidad: ella se "acerca a Dios por los caminos más altos". Esta propuesta no satisface a la familia Morla, pues Wanda comenta a Domingo que su madre "me estaba rebatiendo mis ideas diciendo que con ellas no iba a ser nuestra vida sino algo muy bohemia" (147). A esta resistencia se agrega la de la familia Santa Cruz que es incluso más explícita, ya que la madre y las hermanas de Domingo no comparten las ideas de este hermano menor, las que les parecen egoístas e inadecuadas. Pero no hay nada que haga retroceder a Wanda, porque ella ha visto que "la familia en Europa que se constituye sobre base seria y no pide lujo ni inconsciencia sino un bienestar y tranquilidad seguros, es el tipo de la familia feliz en toda tierra" (147).

Wanda va más allá del territorio adjudicado y aprendido en su entorno. Los límites que derriba y los espacios que conquista no la convierten en alguien que rompa con su clase ni con los roles otorgados por la sociedad a las jóvenes de la elite, pero sí en una mujer capaz de definir una vida que incluye trabajar de acuerdo a sus capacidades e intereses y equilibrar lo público y lo privado. En esta línea le dice a Domingo: "usted no se haga ilusiones, no tendrá en mí mujer célebre, intelectual y oradora. Tendrá ante todo su mujer en su hogar. Su amiga en su vida y su compañera de trabajo" (277).

\section{PARÍS: LA CIUDAD MODERNA}

La modernidad plural y heterogénea en continua transformación y desintegración, genera en el sujeto un sentimiento de ambigüedad y angustia, pues la realidad es vivida como oportunidad y amenaza. Ser modernos es "encontrarnos en un entorno que nos promete aventuras, poder, alegría, crecimiento, transformación de nosotros y del mundo y que, al mismo tiempo, amenaza con destruir todo lo que tenemos, todo lo que sabemos, todo lo que somos" (Berman 1988: 1).

El desarrollo y la hegemonía de los "saberes triunfantes" basados en una objetividad científico-racional, junto a la autonomía y la dominación que convierten al hombre en "amo y señor de la naturaleza”, gestan una cultura secularizada que expulsa a Dios. Al prescindir 
de lo sagrado, la modernidad libera al sujeto de todo relato que impida "construir su propia visión de mundo; pero sumerge a ese mismo sujeto en la orfandad que dicha libertad supone" (Hopenhayn 1997: 13).

La joven chilena vive estas experiencias de la modernidad, pues Europa es para ella un espacio que le pone a prueba sus convicciones y a la vez le ofrece oportunidades de enriquecimiento. Wanda percibe en Europa la crisis del fundamento religioso porque observa un continente donde declina la fe; por ello en los templos "no hay indicios de ceremonias. [Hay] iglesias frías, sin velas, sin flores, sin fieles, sin Sacramento" (85). Por otra parte, en el viejo mundo encuentra una civilización científico-técnica con "maquinarias, ingeniería, edificaciones, cirugía, rascacielos, metropolitanos subterráneos, aeroplanos y telégrafo sin hilos" (50), realidades nuevas que imprimen "grandes velocidades" a la vida y a las comunicaciones y que son valoradas por Wanda. Por último, la dimensión de la modernidad europea que ella más aprecia es "la Europa artística", que le resulta "interesante, sabia y llena de grandes inquietudes" (308). Revisemos algunas de estas últimas experiencias ligadas al arte en París.

París es la ciudad moderna y cosmopolita de las multitudes donde halla "hombres de todas las castas, de todas clases, de todas razas, ideas y religiones" (58). Con lucidez, Wanda comprende que esta cultura de la mezcla ha contribuido a formar el arte galo y que este campo cultural acoge y exhibe las nuevas tendencias, pero al mismo tiempo resguarda y enseña la memoria de la tradición, dualidad que le otorga un espesor único a la capital francesa. París es también la ciudad que le cuestiona sus convicciones plásticas y luego le permite apreciar "la tradición de la ruptura". Distanciada de su cultura de origen, esta urbe europea es para Wanda una ciudad compleja, abierta, móvil, con un campo cultural autónomo y "libertades excepcionales de expresión", que le resulta un espectáculo deslumbrante y lleno de posibilidades. Ella se da cuenta que "conociendo más la gran ciudad he reconocido en ella mis gustos, y mi carácter teniendo un campo vasto se ha desarrollado mucho más libre, con mayor libertad que lo que hubiera conseguido desarrollarse en otra parte" (98).

$\mathrm{Al}$ mismo tiempo, París le resulta una pesadilla que cuestiona sus creencias artísticoculturales aprendidas en Chile. A Pablo Picasso lo rechaza al llegar a París. En 1921 confiesa que es el "creador de la pintura más incomprensible", de "la pintura más fea que se ha visto"(51). Eugenia Huici tiene en su casa el "Retrato de un hombre afirmado en una mesa" del pintor español. Wanda dice que lo ha "mirado con buena voluntad", pero agrega: "inútil; cerrando un ojo, abriendo los dos, de lejos, de cerca, de pie y de cabeza, y todo ha sido inútil" (51). Formada en los parámetros de la mímesis realista que valora la representación figurativa, le pregunta a Eugenia si en el cuadro "ve el hombre, le ruego que me dé un derrotero, que me inicie en la ciencia" (51).

A pesar de este desencuentro inicial, Wanda con el tiempo modifica sus ideas porque asiste a exposiciones, lee libros y revistas hasta que logra entender el cubismo. Después de ver la exposición "Cien años de pintura francesa", concluye: "el espíritu que no es porfiado puede entrar fácilmente en la comprensión modernista" $(104)^{5}$. Como prueba de ello sostiene que en el presente le producen horror las "obras de academia demasiado hechas y de una realidad sin interés". En cambio, le atraen los pintores más contemporáneos: "el gusto que sentí frente a un Cézanne, a un Matisse, a un Manet y otros aún más avanzados" (104). Su enriquecimiento plástico le lleva a aceptar ser retratada por su gran amiga Sara Malvar, chilena que vive en París y que comprende muy bien el conjunto de las vanguardias y las interrelaciones del arte moderno. Sara, señala Wanda, "pinta a la témpera un retrato

5 La exposición "Cien años de pintura francesa" incluyó obras desde Jean-Auguste-Dominique Ingres a Georges Braque y fue organizada por André Lhote y Jacques Émile Blanche con catálogo del primero. 
mío que a todos horroriza porque es de colores violentos y con una composición muy osada, un cuello largo de gacela a lo Modigliani y unos ojos turquesa de iniciada" $(278)^{6}$.

La música es lo que Wanda conoce bien, de modo que ella refiere la riqueza de lo antiguo y lo nuevo que se presenta en París. Al llegar a Francia señala: "tengo hambre de oír un Bach bien clásico, un Beethoven sereno, mi Schumann genial y los Debussy transparentes" (49). Toca piano en su departamento, "los estudios de Krebs, de Puchna, un concierto sencillísimo de Beethoven, Mendels [s] ohn y Scarlatti, todo desfiló por el teclado, insípido" (117), adquiere la guía de conciertos, asiste a una iglesia protestante para escuchar audiciones de oratorios, corales y cantatas de Bach, a ensayos de los precursores de Bach y de Cesar Franck en las iglesias de L'Etoile y San Eustache, a otros ensayos privados de Gustave Bret, y a conciertos de piano y orquesta de Ferruccio Busoni en el antiguo conservatorio. Además va a conferencias y diálogos, conoce a Abel Decaux, profesor de órgano y organista del Sacré-Coeur de Montmartre, toma clases con el organista Marcel Dupré y sus apuntes y notas los comenta por carta con Domingo (243):

"Te contaré que Dupré hoy nos tocó tres Grandes Preludios y Fugas y entre ellas una que llaman de Los Maestros Cantores, pues tiene una frase que es la que continuamente sale en relieve entretejida con todas, que es igual a una del Preludio de Wagner:"

\begin{abstract}
"Tocó también al final la Gran Fantasía en sol menor (Preludio y Fuga) en una forma maravillosa y para afirmar lo que me había dicho M. Decaux, repitió que solo en Francia era donde se conservaba la verdadera tradición organística de Bach, pues Maestros belgas habían ido a beber en la fuente misma, y a su vez los organistas franceses habían ido donde los belgas; así Widor y Guilmant pasaron cada cual dos años junto a Lemenz, quien a su vez había pasado años recogiendo la tradición sagrada de manos de Hesse, organista de una ciudad de Alemania".
\end{abstract}

La música contemporánea también le atrae y explica con detalle. El 23 de marzo de 1922 va al concierto ruso en El Trocadero. Se "ejecutó Une nuit sur le Mont Chauve y una parte de la Kovantchina, ópera de Mussorgsky, Schérézadé de Rimsky-Korsakov, y Petrushka de Stravinsky, esto último me pareció extraordinario, lleno de vida, si se puede decir; lleno de electricidad. Mussorgsky quedaba muy musical, pero al paso lento de los fiacres de hace cincuenta años" (104). Igor Stravinsky le parece que es un compositor no "para piano, es demasiada riqueza de timbres, solo la orquesta le sirve y en Petrushka Stravinsky introduce un piano de gran cola en el conjunto orquestal, lo que es de gran efecto" (104).

Le escribe a Domingo el 2 de junio de 1922: "Mañana en la Ópera hay una premiére de Stravinsky: Mâvra, ballet ruso, además darán Le Sacre du Printemps y Petrushka. Iremos y llevaré mi partitura nueva del Sacre. Será interesantísimo" (189). Al día siguiente le da sus impresiones (191):

"Le Sacreme resultó confuso; como fue lo primero, me desorientó, nunca lo había oído en orquesta, además la partitura no sirvió sino para embrollarme pues estaba oscurísimo y no podía leer ... Debe de oírse mucho la música de Stravinsky para gustar de ella; al principio, el tacto auditivo falla, no se abarca nada en claro y todo se oye borroneado. Así me sucedió también con Mâvra, ópera cómica en un acto de orquestación modernista pero tallada 'sur un fond de robe 1890'”.

"Una ópera sentimental, alegre, fresca, con giros en el canto italiano, de Rossini -o de algo así-, muy lejos de la música moderna o rusa, acompañados por unas voces de instrumentos perfectamente

6 Sara Malvar fue pintora, vivió en Madrid y en 1920 se trasladó a París. Casada con el pintor chileno José Backhaus, al quedar viuda en París en 1922, regresó a Chile en 1923 y escribió excelentes crónicas en las Notas de Arte de Juan Emar. Ver Lizama 2003. 
armónicos pero en tonos disonantes, a veces desvariante, como si todos los músicos estuvieran afiebrados, incluso los cantantes".

El 14 de junio va de nuevo a ver a Igor Stravinsky y el comentario es distinto pues al igual que le ocurre con la pintura, la continua frecuentación de lo nuevo le permite modificar sus creencias: "Ahora sí que entendí la música y [pude] apreciar el conjunto. La Consagración de la Primavera, a pesar de tener como sous-titre: (Scènes de la Russie Païenne), me hizo el efecto de una cosa abstracta como idea, ni féerica ni humana, ni pagana ni mitológica" (240). Agrega (240):

\begin{abstract}
"Se inicia con un preludio que llama la atención por su adormecida expresión, algo que hace sentir la quietud de las siestas que duermen las serpientes al sol mientras una cigarra de lejos chirría. Interesante te resultará ver la partitura, que te mandaré mañana con la explicación que le da su autor. Te explicaré la acción coreográfica muy extraña y desorientadora y eso quedará en tus manos para cuando la quieras ver ... ¿sabes que Mâvra me gustó mucho? Tiene un encanto de ópera italiana, ingenua, fresca en ambiente ruso y expresión musical modernísima. Es curioso cómo un conjunto así resulte gracioso".
\end{abstract}

Los ballets rusos de Diaghilev son otras expresiones artísticas que ella ve con entusiasmo en el teatro de La Ópera y después en el Teatro Mogador donde se instala más tarde la compañía. Le cuenta a Domingo el 17 de junio de 1922: "En el programa está, además de Petrushka, La belle au bois dormant (Tchaikovsky) -Scheherezade (Rimsky-Korsakov), Les Sylphides (Chopin), Le Spectre de la Rose (sur Linvitation a la valse), de Weber, Le Carnaval (de Schumann), Le prince Igor (de Borodin). Como te estaba contando de los ballets, además de todo el repertorio ya explicado tienen (y lo he dejado al último de la enumeración por ser más interesante) Le Chout ou Le Bouffon, de Prokofiev. Les Contes Ruses, de Liadow. L'Aprés midi d'un Faune, de Debussy y Les femmes de bonne humeur, de Scarlatti. Esto último debe de tener olor a Mâvra" (250-251).

Las reflexiones de Wanda sobre los orígenes y los vínculos de la música con la modernidad, aportan una última dimensión. La base de la música nueva según ella tiene "la influencia oriental aportada por Borodin. Se ve clara la influencia morisca venida de España, se ve en muchas composiciones las formas de Bach; la fuga, la polifonía, y es de todas estas influencias que nace la música moderna francesa, que a mi parecer está en su ciclo de desarrollo" (55). La velocidad y la dinámica de la vida moderna son para la joven Morla expresiones que explican el porqué de los ritmos musicales emergentes. Stravinsky, dice Wanda, "con un ritmo sostenido se muestra digno contemporáneo de las grandes velocidades como ser autos, taxis, Metropolitain, aeroplanos y telégrafos sin hilo" (104). En otra ocasión insiste y expande este orden de relaciones: "en este siglo donde el triunfo de las máquinas y la velocidad es manifiesta, donde todo corre vertiginosamente, donde todo lo que se dice se grita, donde triunfan los Jazz-Bands de negros americanos, es de cajón que la música tome ritmos locos y saque timbres estridentes. Ese es el efecto que me hizo uno de los momentos animados de Petrushka" (111-112).

\title{
PALABRAS FINALES
}

Wanda y Domingo se casan el 18 de enero de 1923 en París. En abril de 1923, desde Madrid, Wanda le escribe a su madre que está en Chile y la llama a no dejar "que se borre de tu mente toda la luminaria intelectual y artística de Europa”. Le dice (525):

"No pierdas el hilo y conserva ese ambiente que teníamos en París en nuestros rincones queridos de Rue Lisbonne o de Rue Bayard. Recuerda las sesiones de pintura con Pepe y Sara, el terremoto 
de Hernández, los tés en que se devoraba pan con mantequilla discutiendo con Celia Castro en presencia de Eugenia tartamuda de emoción... Recuerda los cursos de Dupré en el órgano de la Salle Gaveau y nuestras tocatas nocturnas, de los Preludios y Fugas de Bach, las idas al teatro Champs-Elysées, en pleno invierno, amenazando nieve o lluvia a oír a Zacconi o a Stanislavski; los conciertos de Wiener o Stravinsky. Todo eso mamacita es la vida intensamente vivida y vale lo que no se puede pagar con nada, pues es el recuerdo único de los tiempos que pasamos tan juntas ... Esa época al fin, en que pasaba madurando en mi corazón el ideal de felicidad que ahora he realizado, tendrá para mí el encanto de la época más vibrante de mi vida”.

La publicación del libro de cartas impide que se borre "la vida intensamente vivida" de Wanda Morla Lynch y saca a la luz una época esencial del arte contemporáneo vista a través de una testigo privilegiada para apreciarla. El epistolario representa además un material de gran valor para el conocimiento e investigación de la música universal y chilena, junto con ofrecer nuevas imágenes acerca de Domingo Santa Cruz Wilson, uno de sus fundadores.

En este sentido, un estudio que aborde las cartas de Wanda junto a los comentarios referidos a ella y a su vida en conjunto que aporta Santa Cruz en Mi vida en la música, no solo puede contribuir a enriquecer la mirada sobre la actividad artística de esos años, sino que también permitiría develar una faceta de este músico ligada a su vida afectiva, dimensión que contrasta con el perfil más conocido del hombre ejecutivo, fuerte y decidido que figura en sus escritos histórico-musicales.

Asimismo, y al igual que Mi vida en la música, que es el libro de memorias de Santa Cruz, Pájaro libre como soy es un registro que semejante a un diario de vida, nos abre al espacio reflexivo y a la conciencia íntima de quienes experimentaron el tránsito entre dos formas de vivir la modernidad, en una época en que las diferencias en el amor, el arte, la cultura y la vida urbana eran ostensibles. Por último, es una historia amorosa que permite conocer cómo un encuentro fortuito les cambió la vida a dos jóvenes chilenos en Europa.

\section{OBRAS CITADAS}

\section{Berman, Marshall}

1991 Todo lo sólido se desvanece en el aire. Cuarta edición. Madrid: Siglo XXI.

\section{Díaz, Wenceslao}

2004 Juan Francisco González: cartas y otros documentos de su época. Santiago: Ril Editores.

2010 Bohemios en París: epistolario de artistas chilenos en Europa. 1900-1940. Santiago: Ril Editores.

Lizama, Patricio

2003 Notas de Arte. Jean Emar en La Nación (1923-1927). Santiago: DIBAM, Centro de Investigaciones Diego Barros Arana, Ril Editores.

\section{Hopenhayn, Martin}

1997 Después del nihilismo. De Nietzsche a Foucault. Santiago: Andrés Bello.

Morla, Wanda

2013 Pájaro libre como soy. Cartas de Wanda Morla Lynch. Edición y notas de Wenceslao Díaz. Santiago: Ediciones Universidad Católica de Chile.

Morla Lynch, Carlos

1958 En España con Federico García Lorca: (páginas de un diario intimo 1928-1936). Madrid: Aguilar. 


\section{Santa Cruz, Domingo}

2007 Mi vida en la música. Contribución al estudio de la vida musical chilena durante el siglo $X X$. Edición y revisión musicológica de Raquel Bustos Valderrama. Santiago: Gobierno de Chile, Consejo Nacional de la Cultura y las Artes, Consejo Nacional del Libro y la Lectura, Ediciones Universidad Católica de Chile. 